\title{
A PERMANÊNCIA DA ESPONTANEIDADE DA CONSCIÊNCIA NO PENSAMENTO DE SARTRE
}

\section{THE STAY OF SPONTANEITY OF CONSCIENCE IN SARTRE'S THOUGHT}

Cristiano Garotti da Silva*

\section{RESUMO}

O objetivo deste artigo é destacar, de modo condensado, a importância e a permanência, em muitas obras sartrianas, do problema da espontaneidade pura ou da consciência na primeira fase de sua produção. Nas obras iniciais do jovem Sartre: $A$ transcendência do ego (1934), A imaginação (1936) e O imaginário (1940), a espontaneidade aparece sempre relacionada à ideia de consciência e contraposta à de inércia, formando dualidades. Sustenta-se também a permanência, a partir do estudo de $O$ ser e o nada (1943), onde o Para-si será erigido por Sartre como espontaneidade consciente. A consciência, que é um ser Para-si, é pura espontaneidade, uma potencialidade criadora que não se deixa objetivar e que deve se direcionar para a sua finalidade, que é a criação da própria existência. Segundo Sartre, é deste modo que a liberdade emergirá do Para-si enquanto espontaneidade.

PALAVRAS-CHAVE: Espontaneidade. Consciência. Fenomenologia. Husserl. Sartre.

\section{ABSTRACT}

The purpose of this article is to highlight, in a condensed way, the importance and permanence, in many Sartre's works, of the problem of pure spontaneity of conscience in the first phase of its production. In the early works of the young Sartre: The Transcendence of the Ego (1934), The Imagination (1936) and The Imaginary (1940), the spontaneity always appears related to the idea of conscience and opposed to the inertia, forming dualities. It is claimed also to stay, from the study of Being and Nothingness (1943), where the For-Itself will be erected by Sartre as a conscious spontaneity. The conscience, which is a being For-Itself, is pure spontaneity, a creative potential who is not objectify, and should be directed to its purpose, which is the creation of existence itself. According to Sartre, this is how liberty will emerge from For-Itself as spontaneity.

KEYWORDS: Spontaneity. Conscience. Phenomenology. Husserl. Sartre.

\footnotetext{
* Doutor em Filosofia pela PUC/SP. Professor do Departamento de Filosofia da PUC Minas. E-mail: cristianogarotti@pucminas.br
} 
Para Sartre, existe uma vinculação direta entre o mundo/objeto e a consciência. Assim, a espontaneidade emerge da consciência, aparecendo sem qualquer motivação, sem uma origem destacada. A consciência é um ser para si, e é pura espontaneidade, potencialidade criadora que não se deixa objetivar. A espontaneidade pura ou da consciência deve se direcionar para a sua finalidade, que é a criação para se tornar consciência imaginante. $\mathrm{O}$ objeto contrasta-se à consciência e, sendo tomado por ela, firma-se como coisa não produzida e projetada pela espontaneidade pura ou da consciência, por estar no mundo, na natureza, e anteceder a essa vinculação.

Percebe-se que Sartre, ao longo da sua produção, sustenta a importância das propostas trazidas pela fenomenologia, em especial, a husserliana; mas, não deixa de radicalizar o filósofo alemão, promovendo uma revisão no seu pensamento de forma irreverente suscitando ferrenhas críticas.

Sobre a espontaneidade da consciência, Sartre, tem uma inspiração inicial a partir da diferença radical afirmada pela fenomenologia husserliana, que visou estabelecer a vinculação distintiva acima destacada. $\mathrm{O}$ modo de ser das coisas, visado pela consciência e o modo de ser ou aparecer para a consciência apresentam uma distinção em Husserl (HUSSERL, 1913/1950, $\S 46$, p. 106-110). Evoca Husserl, na sequência, a ideia de uma consciência fechada em si, na qual nada pode penetrar, sendo que a existência das coisas jamais seria exigida por ela:

\begin{abstract}
A despeito de todos os discursos que falam, certamente com bom fundamento de sentido, de um ser real do eu humano, de seus vividos de consciência no mundo e de tudo o que a ele pertence em termos de nexos 'psicofísicos' -, a despeito disso tudo, está claro, portanto, que a consciência, considerada em sua 'pureza', tem de valer como uma concatenação de ser fechada por si, como uma concatenação do ser absoluto, no qual nada pode penetrar e do qual nada pode escapulir; que não tem nenhum lado de fora espaço-temporal e não pode estar em nenhum nexo espaçotemporal, que não pode sofrer causalidade de coisa alguma, nem exercer causalidade sobre coisa nenhuma - supondo-se que causalidade tenha o sentido normal de causalidade natural, enquanto relação de dependência entre realidades. (HUSSERL, 1913/1950, § 49, p. 117, grifos do autor).
\end{abstract}

Sartre interpretará esse absoluto intransponível husserliano, fechado em si mesmo, como sendo a espontaneidade da consciência. A espontaneidade compõe uma só coisa com a consciência, formando um conjunto. Depois dotará essa mesma espontaneidade de um poder criacional locupletando-se do conceito husserliano. Posteriormente, abandonando as questões constitutivas do pensamento de Husserl, designará a independência das coisas transcendentes 
ao olhar da consciência. Sartre abandona os conceitos do filósofo alemão no que tange à espontaneidade, pois para este a consciência espontânea é destacada como ingênua, sendo que para Sartre somente a reflexão é o que permitirá um esclarecimento da vida intencional. Sartre entende que a consciência reflexiva produz uma alteração nos conteúdos apreendidos, por isso não deve ser valorizada.

No entanto, Sartre, com base em Husserl, decreta a independência e a excelência da consciência irreflexiva. A posição original e espontânea da consciência ocorre inicialmente no irreflexivo, diante da sua preexistência em relação ao mundo. Essa posição é a pura manifestação do mundo na existência do indivíduo. Desta feita, a espontaneidade emerge primeiramente quando a consciência encontra-se na sua pureza e na sua impessoalidade original, posição esta de irreflexão. O objeto está no mundo e corresponde a ele, e seu resgate, vinculação e revelação, tal como é, são proporcionados pela consciência. A consciência irreflexiva, segundo Sartre, se desdobra em unidade imanente e unidade transcendente, sendo que a primeira é desenvolvida pela própria consciência, no curso temporal e sintético, e a segunda depende do próprio objeto.

Por outro lado, Sartre admitirá a inércia das coisas na sua autonomia e independência, com a consequente contraposição ao olhar da consciência. Nessa polarização proposta por Sartre não há mais qualquer influência de Husserl. A consciência se faz absoluta, porque não é gerada como substância ou essência. A inércia é discriminada por Sartre como a existência em si, exterioridade que se mantém independente da consciência e que se apresenta em dois tipos de existência: como coisa ou como imagem. Por vincular-se à materialidade do mundo e das coisas, apresenta-se como imagem inerte, sendo estranha inicialmente à consciência e não controlada por ela. A percepção da imagem por parte da consciência depende do reconhecimento da inércia, algo que Husserl não aborda. O conteúdo inerte torna-se intencional fazendo com que a imagem do objeto se mantenha, mas não permanece na condição de conteúdo inerte, por causa da atuação da consciência. A continuidade de discussão do problema da inércia não será aqui realizada, pois depende de maiores estudos da Critique de la raison dialectique.

Somente a espontaneidade da consciência conduz o indivíduo a um processo de separação entre os dois tipos de existências, além de contribuir para a atividade de apreensão da imagem e de formação dos pensamentos sobre a imagem. Percebe-se com isso que as duas categorias não podem ser pensadas separadamente no universo dos escritos sartrianos, são indispensáveis e permanentes ao longo da sua produção. O filósofo dá uma maior importância 
nos seus escritos iniciais à espontaneidade, por estar vinculada à consciência; posteriormente, esta adquirirá em L'être et le néant a função de Para-si, quando o filósofo tratará mais detidamente, no âmbito de suas discussões, sobre a subjetividade.

No entanto, é da espontaneidade da consciência, apontada em obras posteriores a estas primeiras do jovem Sartre, que emerge a base para a criação literária e artística, de que o próprio filósofo foi um protagonista no cenário intelectual francês do século passado. A consciência imaginante produz o objeto efetivando-se como realizante e criadora. Em Qu'estce que la litterature?, obra dedicada a uma reflexão sobre a literatura engajada, que Sartre defende, esboça o uso da espontaneidade para fins criacionais. Assim, o filósofo vincula a espontaneidade ao trabalho de criação literária, da mesma forma que a vinculou em $L a$ transcendance de l'ego a um processo de criação da própria existência a partir da consciência. Esse processo de criação da própria existência exposto em La transcendance de l'ego, confirmado em L'imaginaire, e acima relembrado, pode ser vinculado à arte ou à criação literária, assim como à moral, como bem destacou Sartre na sua conferência L'existentialisme est un humanisme, quando pretendeu delinear a moral existencialista: "O mesmo se passa no plano da moral. O que há de comum entre a arte e a moral é que, nos dois casos, temos criação e invenção. Não podemos decidir a priori o que há a fazer." (SARTRE, 1945/1960, p. 77). Vale destacar que as palavras criação e invenção, tanto na língua francesa quanto na nossa língua portuguesa são sinônimas. Mas, o filósofo percebe a semelhança entre a arte e a moral, nas funções de criação e invenção. Da mesma forma que o artista cria sua obra sem os balizamentos dos valores estéticos preestabelecidos, assim também o homem inventa seus valores. O artista, ao concluir sua obra, vê emergir os valores estéticos. Por isso não se pode falar em gratuidade de uma obra de arte. Assim se pode conjecturar que a tão aludida invenção da ação moral sartriana dependeria também da espontaneidade da consciência. Essa citada moral da invenção e da ação sartriana é referida nessa obra e também nos Cahiers pour une morale: "É preciso, portanto, querer o homem. Não descobri-lo, mas inventá-lo." (SARTRE, 1983, p. 23). Correlacionando as duas últimas citações, podemos compreender que o homem tem um futuro a ser criado e está condenado a se inventar. Esse é um dos pilares do existencialismo sartriano, apresentado e sustentado em várias obras. Veja-se a extensão que o filósofo dá ao sentido de criação, enquanto potencialidade da espontaneidade da consciência.

$\mathrm{Na}$ passagem das três primeiras obras indicadas - La transcendance de l'ego, L'imagination e L'imaginaire -, para a mais significativa produção da primeira fase do filósofo, qual seja, L'être et le néant, ocorre uma metamorfose conceitual da contraposição 
dual referida acima, que é confirmada por CAEYMAEX (2005):

\begin{abstract}
Já se pode falar de uma relação negativa entre espontaneidade e inércia: diz-se inerte tudo que recai fora do absoluto da consciência, tudo o que não é espontaneidade. Essa relação negativa assumirá toda a sua significação na ontologia de $O$ ser $e O$ nada, que afirma que o Para-si ou a consciência é "nadificação" do ser. A diferença pura, interna, entre o Para-si e o Em-si substitui assim a diferença até aqui ainda simplesmente oposicional entre a espontaneidade da consciência e a inércia das coisas. Essa oposição cede lugar a uma relação de ser nadificante que liga em interioridade o Para-si e o ser-Em-si transfenomenal que, como tal, é o que é sem outra qualificação possível que a pura identidade a si, para além de toda atividade e toda passividade. Enquanto tal, e no nível da relação de ser nadificante em geral, qualificar o Em-si como inerte é ainda atribuir-lhe muito, e é o que explica a ascese discursiva ou linguística que ele requer. (CAEYMAEX, 2005, p. 55).
\end{abstract}

Como exposto acima, a ressignificação terminológica operada por Sartre representa uma continuidade da polarização anteriormente construída, o que vai redundar na origem da negação ou do nada na interioridade do ser. Essa ressignificação enuncia novos rumos, no seguinte sentido: o Para-si que se afirma enquanto espontaneidade consciente é e só pode ser relação com o Em-si que se afirma enquanto inércia, configurando-se como fundamento da negatividade. Trabalharemos a partir de agora no esforço de demarcar apenas a expressão da espontaneidade consciente em L'être et le néant como vinculada ao Para-si.

\title{
II.
}

Toma-se como referência inicial, a definição do Para-si sartriano esboçada em L'être et le néant, abrangendo uma descrição das suas estruturas imediatas. $\mathrm{O}$ filósofo aborda a ideia de cogito pré-reflexivo como aquele que apresenta uma realidade imediata, a consciência, o ser do Para-si. E a consciência, como apelo de Ser, revela outra realidade, o Em-si. Observando que a elucidação do sentido do Ser só é válida para o Ser do fenômeno, Sartre procura afinal caracterizar o ser-Em-si, ainda que de maneira provisória como: não criado, sem razão que o fundamente, sem qualquer relação com outro ser - ele é; nem passividade e nem atividade, além da negação e da afirmação, basta-se a si mesmo - é em si; cheio de si, maciço, sem segredo, opaco a si mesmo, já que é plena positividade, não conhece a alteridade - é o que é.

Sustenta Sartre, ao contrário de Husserl, que a consciência irreflexiva, possibilita ainda assim a reflexão, pois há um cogito pré-reflexivo que é o suporte para a atividade do cogito cartesiano. Discutindo o cogito cartesiano, percebe-se que este se manifesta como uma 
existência irreflexiva do Ser da consciência, que institui a espontaneidade pura. Entende-se que nada pode capturar a espontaneidade pura, demonstrando esta plena independência inclusive da consciência. Nesse contexto, Sartre estabelece a primeira função da espontaneidade pura em L'être et le néant, sem ainda defini-la claramente neste primeiro momento. Assim justifica a função da espontaneidade pura: “[...] a consciência não poderia sair de sua subjetividade se esta lhe fosse previamente dada, nem agir sobre o ser transcendente ou suportar sem contradição os elementos de passividade necessários para constituir deles um ser transcendente [...]" (SARTRE, 1943/1957, p. 31). Se se convence de que a passividade do Ser do fenômeno está vinculada com a consciência, do mesmo modo se converterá em passividade, por estar vinculada plenamente ao fenômeno, visto que, pela lei de ação e reação, aquele que é agente se tornará também paciente. Discute o filósofo argumentando: "Que parte da passividade pode ser destinada à percepção, ao conhecimento? Ambos são pura atividade, pura espontaneidade.” (SARTRE, 1943/1957, p. 26). É assim, segundo Sartre, que o Ser transfenomenal vai ser considerado em si mesmo.

No entender sartriano, a facticidade do Para-si redunda em duas formas de contingência: a sua própria, já que é o fundamento do seu próprio nada; e aquela que vem do Em-si, que não pode fundamentar a si mesma, nem os outros seres, pois é contrária ao Para-si. Não cabe pois em Sartre a hipótese da concepção de um ser "causa-sui", pois o Para-si é contingente a partir do nada, ocupando essa função na estruturação da liberdade humana. Logo, o "Si", originado de um Ser-Em-si fracassado, por sempre ultrapassar-se em direção a uma coincidência consigo mesmo, nunca é permitido, isto é o que dá sentido à realidade humana. Esse fracasso produz o valor como uma característica importante do Para-si. Isto se configura no possível, como estrutura de um ideal perseguido. Assim, Sartre apresenta o relacionamento do Para-si com o possível, que ele é, fazendo emergir o famoso circuito da ipseidade, como uma das suas estruturas imediatas, assim denominado como: “[...] a relação do Para-si com o possível que ele é, e o 'mundo' como a totalidade de ser na medida em que é atravessada [...]” (SARTRE, 1943/1957, p. 146). O inacabamento do Para-si, tão propalado por Sartre e o isolamento de si mesmo proporcionado pelo mundo ao Para-si foram influenciados indiretamente pela concepção heideggeriana de Sein und Zeit no sentido de como a realidade humana se apresenta, tentando identificar outras estruturas para descrever como o Ser se mostra no mundo.

O filósofo se apoia na construção de uma ontologia da temporalidade para continuar sua descrição das estruturas imediatas do Para-si, estudando inicialmente o antes e o depois, 
no formato de uma estática da temporalidade; criticando os que separam os dois momentos, por demandar um unificador exterior, como aqueles que percebem apenas uma relação de imanência, ignorando a continuidade. Em L'imaginaire já se vislumbra certos embriões dessa formulação da temporalidade sartriana. Mas, agora, Sartre sustenta a existência de um tempo original do Para-si, diverso do tempo do mundo, apresentando um caráter diaspórico, coeso profundamente, além de disperso. Vê-se que o filósofo formula, portanto, a ideia de que passado, presente e futuro estão unidos indissoluvelmente naquilo que se denomina temporalidade. Quando se volta para aquilo que era (Em-si), para o que não é ainda (consciência de certo possível), e para o que era, tendo de ser o que ainda não é, formula-se assim a conjunção da indissolubilidade acima destacada, que é trazida ao mundo pela realidade humana. Sartre adota um ponto de vista sobre o tempo múltiplo real, criticando em parte o instantaneísmo cartesiano e aderindo a certos pontos de vista de Bergson sobre a duração ${ }^{1}$. Logo, o que faculta a união da consciência é o nada, que nunca é superado, emergindo na origem da consciência que admite a temporalidade.

Enfocando-se agora a questão da espontaneidade da consciência no âmbito do Para-si, verifica-se que este tem uma dinâmica temporal própria que apresenta uma estrutura que “tem-de-ser" seu próprio nada e lidar com a mudança: "Mas a mudança pertence naturalmente ao Para-si, na medida que esse Para-si é espontaneidade.” (SARTRE, 1943/1957, p. 194). As suas identidades se confundem, como se pode perceber pela citação do filósofo. Destaca-se que a espontaneidade consciente, que se define por si mesma ou deveria deixar-se definir, é vinculada ao Para-si. Sendo assim, a espontaneidade é condicionada a praticar a negação diante daquilo que posiciona, sob pena de se estabelecer nesse ser que adquiriu. E mesmo diante da própria negação realizada, a espontaneidade é condicionada a renegá-la, diante da possibilidade de tornar-se inerte, estendendo assim sua existência. Observe-se que Sartre ressalta o caráter fugidio, não permanente da espontaneidade: ela só tem sentido se evadir de si mesma e se evadir da própria negação, sendo constantemente mutável. Sabe-se que a espontaneidade necessita da temporalidade para a prática do prolongamento e da aquisição acima referidos, sem na verdade se temporalizar, já que ela mesma faz parte do adquirido pelo meio da negação: "Sua natureza peculiar consiste em não aproveitar o adquirido que ela constitui ao realizar-se como espontaneidade." (SARTRE, 1943/1957, p. 195). Nada pode ser

\footnotetext{
${ }^{1}$ Sartre toma a ideia de duração de Bergson, no sentido de atributo dos estados psíquicos que decorrem uns dos outros, sem no entanto se conjugarem. Leiamos: "A duração pura é a forma que toma a sucessão de nossos estados de consciência, quando nosso $e u$ se deixa viver e quando se abstém de estabelecer uma separação entre o estado presente e os estados anteriores". (Essai sur les données immédiates de la conscience, p. 74-75).
} 
pensado sem a temporalidade; temporalizamos para fazer surgir o tempo, no entanto a espontaneidade é intemporal. Nesse ponto, Sartre faz alusão a Kant, que na Kritik der reinen Vernunft considera a espontaneidade intemporal como não aceitável, mas que não pode ser contraditória. Parece aderir a parte do pensamento kantiano sobre a espontaneidade, embora Sartre continue insistindo que a espontaneidade é intemporal. Sendo assim, a própria temporalização se faz irreversível, e o Para-si adquire esse caráter irreversível de "posicionamento-negação" que nunca se encerra, não propiciando plenitude, mas a série "adquiridos-negados" assume uma prioridade ontológica: “[...] tem-de-ser em plena espontaneidade aquilo que será.” (SARTRE, 1943/1957, p. 213). Para Silva (2008),

\footnotetext{
é assim que, segundo Sartre, substancializa-se a absoluta espontaneidade que a consciência é; constitui-se uma substância paralela ao mundo e incapaz de relacionar-se com ele sem mediação (Existência e Perfeição divinas, na quarta meditação). Por isso, o cogito cartesiano deve ser considerado lícito; mas é, também, tributário da estrutura originária da consciência (a pré-reflexividade) que Descartes não se deu conta $\mathrm{e}$, assim, produziu uma teoria que redunda na dualidade substancial. (SILVA, 2008, p. 232).
}

No entender desse comentador, encontra-se aí a afirmação da existência substancial da espontaneidade por parte de Sartre. Percebe-se a vinculação dessa espontaneidade a uma influência da existência irreflexiva cartesiana como Ser do Percipi. Sustenta Sartre que a consciência irreflexiva possibilita ainda assim a reflexão, pois há um cogito pré-reflexivo que é o suporte para a atividade do cogito cartesiano. Discutindo o cogito cartesiano, percebe-se que este se manifesta como uma existência irreflexiva do Ser da consciência, que institui a espontaneidade pura. Enfim, a consciência no seu processo de temporalização conduz a escolha originária a dilatar o tempo, identificando-o com os três ek-stases temporais heideggerianos (passado, presente e futuro). A ontologia sartriana incorpora o pensamento heideggeriano/husserliano, dilatando seu conceito de consciência temporal, desgarrando-se do instantaneísmo cartesiano e da duração bergsoniana, como já dito. Vale lembrar que a autotemporalização da consciência originária é proveniente da espontaneidade como aludiu Husserl, tendo influenciado sobremaneira Sartre. Em Ideen (1913), Husserl destaca a importância da espontaneidade no processo de ideação: “[...] 'a construção dos conceitos' e, da mesma maneira, a livre ficção se efetuam espontaneamente, e aquilo que é gerado espontaneamente é, sem dúvida, um produto do espírito.” (HUSSERL, 1913/1950, p. 50). Referindo-se à construção de conceitos através de outros conceitos, quando o filósofo alemão exemplifica a citação acima com a ficção arbitrária do centauro tocando flauta, Husserl 
declara que o ato de concepção ou ideação necessita da espontaneidade, produto do espírito, diferentemente da consciência empírica que não necessita desta. Para Husserl, pelo significado do conceito que se apresenta, enquanto unidade imanente, supera-se o ponto de vista transcendente da coisa. Segundo Mouillie, "Husserl já havia identificado a autotemporalização da consciência originária com uma gênese espontânea (Lições, suplemento I).” (MOUILLIE 2000, p. 34).

Referendado ainda na exposição do fundamento do Para-si, destaca-se, por fim, que este apresentou-se negando que fosse determinado ser singular, porque sua preocupação era a de desvelar a estrutura da negatividade na relação de conhecimento. Do mesmo modo que Heidegger concebe dentro do nada o Ser aí, sempre para além do ente em sua totalidade, Sartre concebe seu conceito de transcendência em ato de negação interna do Para-si. Desta feita, o fundamento da transcendência em Heidegger está na existência do Dasein; em Sartre, no Para-si. De acordo com Sartre somos transcendência, pois o nada nos isola do Ser que somos, impedindo nossa identidade.

O Para-si efetiva-se também como presença. Todavia, trata-se de uma negatividade secundária, pois uma negatividade como transcendência original não pode ser estipulada a partir de um "isto"; de maneira oposta, deve fazer com que ele exista. Um Ser que em sua presença mostre sua própria totalidade é denominado como presença original, como ocorre com o Para-si que, na sua presença ao Ser, faz com que haja todo o ser, como confirma Sartre: “[...] a presença ao mundo do Para-si só pode se realizar por sua presença a uma ou várias coisas particulares e, reciprocamente, sua presença a uma coisa particular só pode se realizar sobre o fundo de uma presença ao mundo." (SARTRE, 1943/1957, p. 229). Nessa passagem, o caráter ek-stático do Para-si pode ser deduzido, pois provoca a ambiguidade do mundo como totalidade sintética e somatório de todos os "istos". O espaço é produto desse desengano em continuidade, da totalidade em coleção, relação móvel entre séries que não têm qualquer relação, já que são puras exterioridades, o lugar dos “istos”, um nada. Propiciandose vida ao Ser, o Para-si não pode acrescentar nada a ele, pois é idealidade da síntese, ou "a negação da determinação ideal". O Para-si organiza pela espontaneidade seu ser a partir do ato negador relacionando-se às coisas e determinando sua qualidade. $\mathrm{O}$ aparecimento do Parasi não é somente o acontecimento absoluto para o conhecimento, mas algo que acontece com o Em-si.

A liberdade emerge no princípio do Para-si, e este, como já dito, é espontaneidade. Diante da negação interna do Para-si, surgem duas possibilidades: a da propulsão do homem 
em direção ao futuro, ou a temporalização do projeto diante do mundo em direção a diversas possibilidades. O filósofo vai entender que liberdade, escolha, nadificação e temporalização compõem uma mesma coisa, assim tenta descrever a liberdade em maiores detalhes, destacando logo em seguida a tese de uma vontade livre circundada por paixões determinadas. Segundo o filósofo, o estudo da vontade permitirá aquilatar ainda mais a compreensão da liberdade. Inicia a discussão demarcando as relações entre liberdade e vontade, tentando elucidar quais são os atos que exercem poder sobre a vontade livre e quais são os atos que escapam do controle da vontade humana. Para Sartre, ou o homem é inteiramente livre ou inteiramente determinado, não havendo meio termo, sendo injustificável a concepção de uma dualidade no interior da unidade psíquica. É a vontade, enquanto decisão reflexiva a certos fins, que requer, para se formar enquanto tal, uma liberdade originária e contemporânea que a ampare. No entanto, a vontade não é criadora dos fins, pois é reflexiva por essência, ela apenas emoldura os móbeis e fins já posicionados pelo Para-si e organizados pela espontaneidade livre: "A conduta voluntária, ao organizar reflexivamente os meios para alcançar os fins, encara técnica e racionalmente as situações. Como tal, a conduta voluntária é desveladora do mundo técnico.” (MATEO, 1975, p. 34, grifo da autora). Mas a combinação entre espontaneidade consciente e vontade é insustentável, representando uma antinomia. No entanto, sobre a relação liberdade-vontade acima levantada, Mateo também entende que:

\footnotetext{
A compreensão da liberdade sartriana, seu valor ontológico, sua identificação com o nada e seu caráter de fundamento de toda a existência humana e, por fim, de todo comportamento, significa uma superação da tradicional identificação liberdadevontade, tal como se dava em Descartes e Kant. [...] A identificação da liberdade com as ações voluntárias, reflexivas, racionais, impede de perceber nela o fundamento da totalidade a realizar, limita a responsabilidade do homem a respeito de seu comportamento e, deixando de lado o dualismo metafísico que a sustenta, cria um maniqueísmo moral. (MATEO, 1975, p. 32, grifo da autora).
}

Nesse sentido, a liberdade sartriana, vinculando-se à espontaneidade consciente, distancia-se da vontade como tradicionalmente foi constatado na História da Ética. A vontade não se efetiva como a autêntica manifestação da liberdade como em outros pensadores.

Ressalte-se que não existem fenômenos psíquicos superiores à liberdade, nem mesmo a espontaneidade, pois todos a manifestam, todos são maneiras de ser do meu próprio nada. Sendo assim, as paixões e as emoções são consequentemente expressão de uma escolha, existindo um conflito entre consciência e conhecimento no que tange ao mesmo problema.

Ao analisar os motivos e os móbeis, o filósofo destaca que são parecidos, com ligeiras 
diferenças, da mesma forma que a consciência não-tética (de) si é o nexo ontológico de ter consciência do objeto. Para esclarecer melhor, motivo, móbil e fim "[...] são os três termos indissolúveis do brotar de uma consciência viva livre que se projeta rumo às suas possibilidades e define-se por essas possibilidades." (SARTRE, 1943/1957, p. 526). Poder-seia objetar que, efetivando-se a escolha do modo de ser, o Para-si cria um campo de possibilidades escolhendo-se o mundo, não baseado no Em-si, mas no seu sentido - assim escolhemos a nós mesmos. Havendo a soma dos motivos (contemplação das coisas) e dos móbeis (avaliação das condições do mundo) ocorre necessariamente um direcionamento em relação aos fins e efetivamente à escolha. Esse produto consciente vai ser organizado pela espontaneidade pura. Vê-se que os motivos e os móbeis só se efetivarão através do projeto, qualificado como a produção livre do fim. No entanto, antes do projeto, segundo Sartre, há “[...] uma escolha da deliberação como procedimento que irá me anunciar aquilo que é projeto e, por conseguinte, o que sou. E a escolha da deliberação é organizada com o conjunto móbeis-motivos-fins pela espontaneidade livre." (SARTRE, 1943/1957, p. 527). O fundamento da escolha de deliberação requer uma interpretação da escolha originária de maneira consciente, escolha esta que poderá ser alterada. Mais uma vez o filósofo atribui uma característica importante para a espontaneidade livre ou não voluntária, que em L'être et le néant é definida nos mesmos termos anteriores, como a "[...] consciência puramente irreflexiva dos motivos através do puro e simples projeto do ato." (SARTRE, 1943/1957, p. 527-528). Necessariamente por estar vinculada ao irreflexivo, não apresenta função delineada na execução, esta sim, de atribuição da vontade. A espontaneidade irreflexiva emerge de forma contingente e se torna elemento pertencente a um projeto original. Quando Sartre evoca o Para-si no sentido de escolha, aponta-nos para outra dimensão ontológica que o Para-si experimenta, a da angústia ao buscar sua liberdade, pois o Para-si deve escolher seu sentido de ser sem poder se tornar estrutura do próprio ser. Por isso, posteriormente, nos Cahiers pour une morale, Sartre continuará afirmando a importância da espontaneidade como fundamento não só da liberdade, mas da vida moral como um todo: “A base única da vida moral deve ser a espontaneidade, isto é, o imediato, o irreflexivo." ( SARTRE, 1983, p. 12). Mesmo em obra posterior, que seria possivelmente a continuidade desta, o filósofo permanece reafirmando sua ideia.

Sartre, no entanto, separa o ato voluntário da espontaneidade não voluntária, como já havia feito em L'imaginaire, distinguindo vontade de espontaneidade. Em L'imaginaire, na descrição do movimento dos objetos irreais na vida imaginária, Sartre destacava que a 
consciência imaginante se forma em ato único ou por vontade ou por espontaneidade prévoluntária (antecedente da vontade), ressaltando o desenvolvimento que esta podia proporcionar à consciência imaginante, sendo que somente a espontaneidade poderia animar os objetos irreais. Portanto, já havia no entendimento do filósofo uma prevalência da espontaneidade sobre a vontade, só que ele tratava do mundo imaginário e não de ações morais (escolhas) como se refere agora. Mas ainda assim a espontaneidade no seu sentido irreflexivo prevalece como função importante do Para-si na organização deliberativa da liberdade, como seu fundamento. Embora utilizando terminologias um pouco diferentes, estas referem-se à mesma espontaneidade da consciência em L'imaginaire e em obras anteriores. Portanto, o fundamento da liberdade em Sartre é emergente de uma antinomia entre vontade e espontaneidade. Notadamente há um predomínio do irreflexivo sobre o reflexivo no fundamento da liberdade tornando-se um perigoso paradoxo. A vontade não se envolve no projeto original, que não é afetado por estruturas particulares. A escolha fundamental é manejada pelo indivíduo sobre um plano reflexivo, mas organizada pela espontaneidade a partir dos fundamentos do Para-si.

III.

Conclui-se que a espontaneidade e a inércia, que emergiram nas obras iniciais do jovem Sartre, sempre estiveram contrapostas, ambas mantidas na produção continuada do filósofo, nas obras mais reconhecidas. A espontaneidade vinculou-se ao Para-si enquanto liberdade em L'être et le néant, ao passo que, a inércia ao Em-si, enquanto estrutura dialéticonegativa, contrária à práxis, confirmada na Critique de la raison dialectique, que aqui não foi por nós referida. $\mathrm{O}$ artigo obedeceu de maneira retilínea à construção teórica do filósofo em obras sequenciadas ao longo da sua produção.

O objetivo deste artigo foi destacar a importância do problema da espontaneidade pura ou da consciência investido ao longo de parte significativa da obra sartriana, talvez pouco estudada até hoje, embora bastante relevante. A permanência do problema da espontaneidade da consciência nas obras do filósofo é corroborada por Coelho (1978), que cognomina-a como uma das teses basilares de Sartre: "Esta afirmação da espontaneidade radical de toda e qualquer consciência constitui mesmo uma das teses fundamentais da filosofia sartreana ( $\mathrm{sic}$ ), presente em todas suas obras." (COELHO, 1978, p. 251). Confirma-se, portanto, a permanência e a pertinência de aprofundamento de uma temática ainda pouco estudada. 
$\mathrm{Na}$ primeira parte, tratou-se da contraposição entre os conceitos de espontaneidade e inércia, tomando como referência as obras do jovem filósofo, anteriores a L'être et le néant. Apresentou-se a origem da espontaneidade como sendo a consciência na sua pureza e na sua impessoalidade original em La transcendance de l'ego, delineada claramente pelo filósofo como contraponto à inércia das coisas transcendidas. Vimos, a partir de L'imagination, que das análises psicológicas da imagem Sartre depreendeu o conceito de inércia como contraposto ao de espontaneidade. Destacou-se que a inércia faz ao mesmo tempo as coisas preexistirem sem a necessidade de serem vistas, porque já foram captadas, e a espontaneidade da consciência conduz o indivíduo a um processo de separação entre os tipos de existências, como coisa e como imagem, além de desvincular a atividade de apreensão da imagem com a de formação dos pensamentos sobre a imagem. A partir dos estudos de L'imaginaire acompanhamos a elaboração sartriana da definição de espontaneidade da consciência pura e seus desdobramentos, no âmbito de uma consciência imaginante. Indicou-se assim, com a demarcação dessa trajetória uma ressignificação terminológica proporcionada pelo filósofo.

$\mathrm{Na}$ segunda parte, realizou-se uma concisa abordagem de alguns dos elementos da ontologia fenomenológica esboçada em L'être et le néant, em que se visou atingir o objetivo central, que é demarcar a presença da espontaneidade da consciência como que vinculada ao Para-si. Para tal intento, conceituaram-se as regiões do Ser, que oriundas do Ser transfenomenal (Ser Para-si) e do Ser fenomenal do fenômeno (Ser Em-si), formulam uma totalidade sintética. Apresentou-se o núcleo do artigo demonstrando que a consciência, que é um ser Para-si, é pura espontaneidade, potencialidade criadora que não se deixa objetivar, e que deve se direcionar para a sua finalidade, que é a criação da própria existência. O Para-si então foi definido como ser do valor, a partir da descrição de suas estruturas imediatas, como a presença a Si e a facticidade, além da sua relação com o possível na eclosão do circuito da ipseidade. Destacou-se o modo de construção, pelo autor, de uma ontologia da temporalidade a partir da sua estática, sustentando-se a existência de um tempo original do Para-si, diverso do tempo do mundo, que apresenta caráter diaspórico, coeso e disperso, ao formular a ideia de que passado, presente e futuro estão unidos indissoluvelmente naquilo que se denomina temporalidade. Diante desses elementos, a transcendência foi concebida como ato de negação interna do Para-si, além de se proceder a uma explanação sobre as determinações originárias do Ser. Para Sartre, a liberdade é o fenômeno psíquico superior que emerge no fenômeno do Para-si diante da sua negação interna. O Para-si é consciência que institui a espontaneidade pura irreflexiva dos motivos através do puro e simples projeto de ato moral. A espontaneidade 
é configurada como um elemento colateral ao mundo, que apresenta uma dinâmica temporal original que a induz a lidar com seu próprio nada e com a mudança. A escolha de deliberação do projeto é organizada a partir da reunião entre móbeis-motivos-fins pela espontaneidade livre, sendo que o fundamento dela é a compreensão da escolha originária de maneira consciente. A espontaneidade e a vontade se diferenciam e não têm a mesma atividade no plano da liberdade. O fundamento da liberdade é emergente de uma antinomia entre vontade e espontaneidade, em um predomínio do irreflexivo sobre o reflexivo. Portanto, pode-se inferir que a espontaneidade pura ou consciente configura-se como fundamento ontológico da liberdade.

\section{Referências}

BERGSON, Henri. Essai sur les données immédiates de la conscience(1889). In:BERGSON, Henri. Oeuvres. 6. éd. Paris: PUF, 2001. p.1-156.

CAEYMAEX, Florence. Praxis e inertie. La critique de la raison dialectique au miroir de l'ontologie phénoménologique. In: WORMSER, Gérard (Dir.). Jean-Paul Sartre, violence et éthique. Lyon: [Sens] [Public], 2005. p. 42-60.

COELHO, Ildeu Moreira. Sartre e a interrogação fenomenológica do imaginário. 471f. 1978. Tese (Doutorado) - Universidade de São Paulo, São Paulo.

HEIDEGGER, Martin. Sein und Zeit (1927). Tübingen: Max Neimeyer Verlag, 1963.

HUSSERL, Edmund. Ideen zu einer reinen Phanomenologie und phanomenologischen Philosophie (1913). BIEMEL, W.; BIEMEL, M. (Ed.). Haag: M. Nijhoff, 1950-52. 3v.

KANT, Immanuel. Kritik der reinen Vernunft (1787). Berlim: Verlegt Bei Bruno Cassirer, 1923.

MATEO, Martha S. Ontologia y etica en Sartre. Tucuman, Argentina: Univ. Nac. de Tucuman: Facultad de Filosofia y Letras, 1975.

MOUILLIE, Jean-Marc. Sartre: conscience, ego et psychè. Paris: Presses universitaires de France: 2000.

NOUDELMANN, François; PHILIPPE, Gilles. Dictionnaire Sartre. Paris: H. Champion, 2004.

SARTRE, Jean-Paul. Cahiers pour une morale. Paris: Gallimard, 1983.

SARTRE, Jean Paul. Critique de la raison dialectique (1960). Etablissement du texte, notes et glossaire par Arlette Elkaim-Sartre Paris: Gallimard, 1985. 
SARTRE, Jean-Paul. L'être et le néant: essai d'ontologie phenomenologique (1943). 54. ed. Paris: Galimard, 1957.

SARTRE, Jean Paul. L'existentialisme est un humanisme (1945). Paris: Nagel, 1960.

SARTRE, Jean-Paul. L’imagination (1936). Paris: PUF, 1948.

SARTRE, Jean-Paul. L'imaginaire: psychologie phenomenologique de l'imagination. Paris: Gallimard, 1940.

SARTRE, Jean-Paul. La transcendance de l'ego: esquisse d'une description phénoménologique (1934). Paris: J. Vrin, 1985.

SARTRE, Jean-Paul. Qu'est-ce que la littérature? Paris: Gallimard, 1948.

SILVA, Cristiano Garotti da. A espontaneidade da consciência como fundamento ontológico da liberdade em Sartre. 201f. 2015. Tese (Doutorado) - Pontifícia Universidade Católica de São Paulo, São Paulo.

SILVA, Luciano Donizetti da. Tempo e temporalidade na filosofia de Sartre. Princípios, Natal, v.15, n. 24, jul./dez. 2008, p. 225-248. Disponível em: <http://periodicos.ufrn.br/principios/article/view/432/370> Acesso em: 30 out. 2015. 